\title{
FACTORS AFFECTING CHOICE IN A MULTI-STAGE MODEL The Influence of Saliency and Similarity on Retrieval Set and the Implication of Context Effect on Consideration Set
}

\author{
Eric Santosa \\ Unisbank \\ Semarang, Indonesia
}

While it is considered a new paradigm in consumer research, the multi-stage model of consumer decision-making remains unclear as to whether brands are easily retrieved. Likewise, the process of consideration, after particular brands are successfully retrieved, is still in question. This study purports to investigate the effects of saliency and similarity on the ease of retrieval. In addition, referring to some studies of context effect, the effects of attraction, compromise, and assimilation are examined to observe whether they contribute to consideration. A within-subject design is employed in this study. Previously, three preliminary studies are arranged to determine the dominants, new entrants, attributes, and other criteria nominated in the experimental study. The results turn out to be supporting the hypotheses.

Keywords: consideration set; context effect; retrieval set 


\section{Introduction}

The multi-stage model asserts that a choice should be produced from a process of sequence. First of all, a product or a brand that falls into a choice should be available in a retrieval set. The retrieval set consists of products or brands successfully retrieved from all products or brands available in the market. Secondly, a choice should be produced from the retrieved products or brands that are fruitfully considered in a consideration set. Consequently, products or brands not successfully retrieved and/or considered are not potentially taken.

According to literature and previous studies, the process of retrieval is influenced by several factors, such as primacy, recency, distinctiveness, firstmover product, pioneer product, frequency, saliency, the strength of association between the brand node and other active nodes, and the availability of retrieval cues (i.e., category, brand, and attribute). Likewise, the process in the consideration set is affected by some factors, such as price, design, quality, color, etc., which are likely compensatory or non-compensatory. If there are two or more products in a particular situation of similar price, design, quality, or color, which one will be considered? Consumers may find a difficulty making a decision. In such a situation, the theory of attraction effect and compromise effect might be helpful. The theory of attraction effect postulates that a particular product is more likely to be taken than the other when a third product is inserted into the set due to its dominating position. The compromise effect recommends that a particular product pose a compromise position when a third product inserted is more considerably of choice.

Meanwhile, another situation may prevail. While the third product inserted is inferior to the two existing products, whether of a particular attribute or more, how big is its chance to be considered? The dominating product is obviously taken into account. The third will have a high chance too under the circumstances that it is alike to the dominating product. The last situation refers to the theory of assimilated effect. Whether the product exerts domination, compromise, or assimilation should be carried out from the retrieval set. Therefore, the purpose of this study is to examine particular products, whether the existing or the new ones - which pose any of the three effects (i.e., domination, compromise, assimilation) or even two of the three - are products successfully retrieved due to their saliency or similarity. Furthermore, this research aims to investigate whether the attraction effect, the compromise effect, and the assimilation effect work in the consideration set.

The enlightenment of theoretical developments, multi-stage model, retrieval and consideration sets, several empirical investigations and explanations are reported. The findings suggest that the effects of saliency and similarity operate in the retrieval set. 
In addition, the effects of attraction, compromise, and assimilation are also activated in the consideration set. The implications of these findings on consumer decision research are then discussed.

\section{Theoretical Developments}

It is widely believed that choice involves uncertainty about future consequences of current actions and uncertainty as to future preferences regarding those consequences (March 1978; Savage 1954). While there is often uncertainty as to the true values of alternatives of different attributes, consumers may also be uncertain about the weights of the attributes and on their preferences for different combinations of attribute values (Simonson 1989).

Some studies demonstrate that individual choice behavior under preference uncertainty can better be understood when analyzed based on available reasons or justifications for and against each alternative (Montgomery 1983; Slovic 1975; Slovic, Fischhoff and Lichtenstein 1982; Tversky in Simonson 1989). In particular, Montgomery (1983) suggests that decision makers determine that they are prepared to make a choice when they find arguments strong enough for making a decision. Likewise, Slovic (1975) defines that decision makers faced with a need for choosing between two equally valued alternatives tend to prefer the one that is superior in more important attributes.
Bettman (1979) introduced an integration processes theory. According to the theory, in making a decision, consumer is facilitated through two ways: (1) compensatory and (2) noncompensatory integration processes. The compensatory integration process combines all beliefs about the consequences of the choice alternatives to form an overall evaluation toward each alternative. On the other hand, the noncompensatory integration process accounts for beliefs about the positive and negative consequences of the choice alternatives but does not compensate for each other.

Meanwhile, the value maximization (VM) assumption, that each alternative has a utility or subjective value and the consumer selects the alternative with the highest value, is commonly employed (Simonson and Tversky 1992). An implication of the $\mathrm{VM}$ assumption is that the preference between alternatives is independent of the context, which is the set of alternatives under consideration. However, Payne, Bettman, and Johnson (1992) violate the regularity as they proclaim that consumer preferences are influenced by the context of choice. Consequently, if a consumer prefers brand $\mathrm{A}$ to brand $\mathrm{B}$ in one context (e.g., when only $A$ and $B$ are available), then B can also be preferred to $\mathrm{A}$ in another context (e.g., when brand $\mathrm{C}$ is added to the choice set). In other words, under a certain condition, the market share of a given brand increases rather than decreases when a new brand is introduced. 
Attraction effect (Huber et al. 1982; Huber and Puto 1983; Ratneshwar et al. 1987; Pan et al. 1995; Highhouse 1996; Herne 1997; Herne 1999; Amaldoss et al. 2005; Kim and Hasher 2005; Kohler 2007) is in accordance with the context. It explains that a product posing asymmetrical or relatively dominance gets a greater possibility to be chosen when a new alternative, which is asymmetrical or relatively dominated, comes nearby. While allowing a better understanding of consumer choice, it actually leads to the development of compromise effect (Simonson 1989). The compromise effect postulates that an alternative would tend to gain market share when it becomes a compromise or middle option in the set.

While the position of middle option requires more explorations, Pan and Lehmann (1993) observe two models: (1) frequency effect and (2) range effect. Based on the frequency effect, if a new alternative enters to the midst of two existing products, in which it increases the frequency between the two products, the two existing products will be perceived as more dissimilar. Meanwhile, the range effect suggests that if a new alternative comes outside the two existing products, in which it increases the range, the two existing products will be perceived as more similar to each other.

Furthermore, Pan and Lehmann (1993) explore that the frequency and range effects lead to another model known as categorization effect. Actually, this effect was firstly introduced by Lingle, Altom and Medin (1984), and developed by some other researchers such as Cohen and Basu (1987), and Sujan and Bettman (1989). It theorizes that when a new alternative's specifications are similar to a subgroup of existing products, it is likely that the new alternative would be categorized as the subgroup. In a later study, Lehmann and Pan (1994) make use of the term "assimilation" instead of "categorization."

In the meantime, the term "context” refers to a consideration stage. The fact that the alternatives will likely be considered in the consideration stage fingers out that there is a stage beforehand that impels options to be valuably considered. In other words, there is possibly a phase that primarily selects particular numbers out of some other numbers. The concept of choice being limited to a small number of brands, which are brands a buyer considers when he/she contemplates purchasing a unit of the product class, is known as the evoked set (Howard 1989). In accordance with the idea, Howard and Sheth (in Lunn 1974) generate an exclusive model that focuses on memory base. The concept of memory-based decision making itself denotes the decision making deduced from information saved in memory (Lynch and Srull in Kardes 2002).

Following a particular stream, some researches find out that at least consumers use a two-stage process when making a choice (Alba and Chattopadhyay 1985; Johnson and Payne 1985; Alba and Hutchinson 
1987; Hauser and Wernerfelt 1990; Robert and Lattin 1991). However, most do not expound clearly on what criteria used in screening products, particularly from stage 1 to stage 2, except Johnson and Payne (1985) who clarify that available alternatives are first screened on the basis of a simple non-compensatory rule (stage 1 ) and the remaining alternatives are analyzed more carefully using a compensatory rule (stage 2). In addition, Hauser and Wernerfelt (1990) employ the cost evaluation as a standard whereas Robert and Lattin (1991) operate a tradeoff between cost and value considerations.

Later on, some research develops more than two stages in choice decision making (Nedungadi 1990; Shocker etal. 1991; Kardes et al. 1993). A choice should be produced from a process of sequence starting from a universal set to retrieval set and consideration set, and ending in choice. The process is renowned as the multistage model.

\section{Multi-stage Model}

The multi-stage model was initiated by Shocker et al. (1991). Encouraged by the stream of memory-based decision making, it accordingly consists of universal set, retrieval set, consideration set, and choice. The universal set refers to all brands available in the market place. The retrieval set comprises the subset of brands in the universal set that consumers can access from memory. Not all brands exposed to consumers would be encoded and saved into the memory; hence, the retrieval set is much smaller than the universal set (Alba and Chattopadhyay 1985, 1986). The consideration set is composed of the subset of brands in

Figure 1. Multi-stage Model

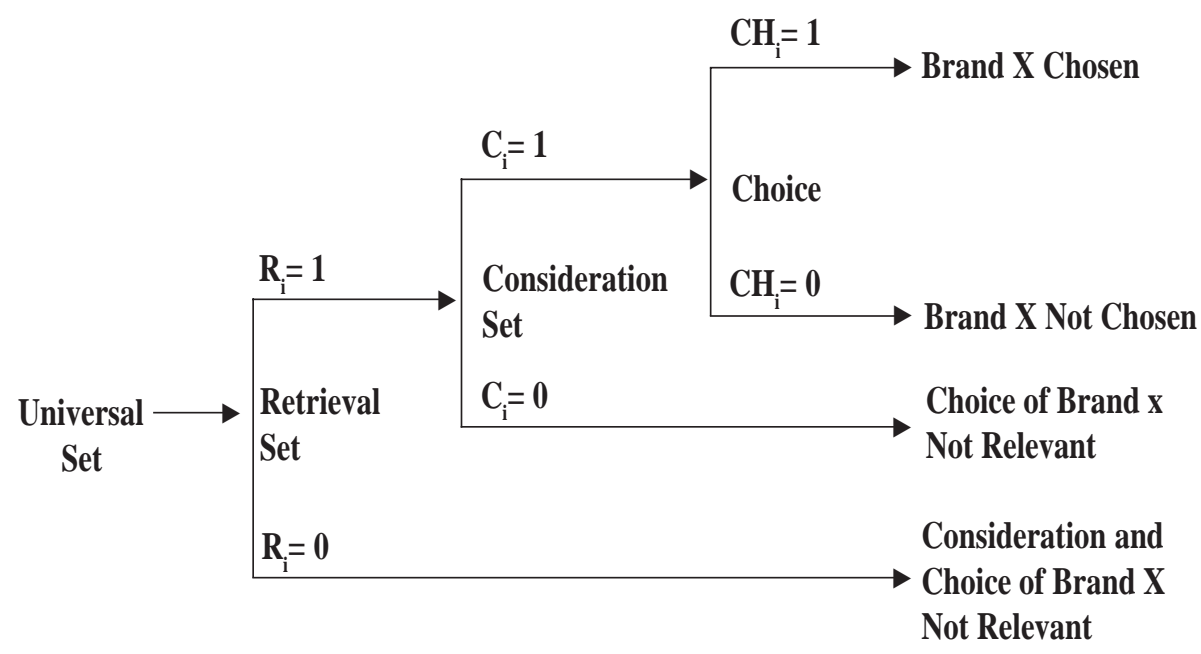

Source: Kardes et al. (1993) 
the retrieval set scrutinized carefully in a particular choice occurrence. Since consumers may not consider all brands retrieved, the consideration set is often smaller than the retrieval set. Finally, one brand is selected from the consideration set (Figure 1).

As shown in Figure 1, not all products available in the market are captured and stored in a consumer's memory; in fact, only a few are successfully retrieved. If a particular product does not appear in the retrieval set, it will not emerge either in the consideration set, meaning that it is impossible to become a choice. In other words, a particular product not successfully retrieved is irrelevant to the consideration and choice. On the other hand, a particular product that appears in the retrieval set is not necessarily considered or chosen. Accordingly, a choice is a particular product successfully retrieved and considered.

\section{Brand Retrieval}

Consumers obtain product information from many sources, such as advertisements, packages, point of purchase displays, word-of-mouth communications, and magazines (Kardes et al. 1993). Basically, information can be classified into three types: (1) item information, (2) associative information, and (3) serial order information ( $\mathrm{Li}$ and Lewandowsky 1995). The item information records the occurrences of events; the associative information is required to remember the relationships among separate events, while the serial order information records the temporal sequence of a string of events. Such information must be stored and readable whenever needed, or otherwise invaluable. It embraces three stages: (1) encoding, (2) storage, and (3) retrieval (Restle 1975).

While any information stored is likely to be recalled, it suffers from the problem of priority: which one should be prioritized, the first one or the last one? Li and Lewandowsky (1995) suggest that retrieval involves two directions: (1) forward and (2) backward recalls. When the process of recall is in the forward direction, it is instructed to recall a list from the beginning to the end. Data indicate extensive primacy (advantages for early list items) and little recency (advantages for late list items). On the contrary, the backward direction means that primacy is minimum, and recency tends to be much steeper.

The primacy effect implies a higher possibility for an item initially stored to be recalled following the forward direction. The recency effect is the opposite, which is a higher possibility for lastly stored following the backward direction (Li and Lewandowsky 1995). Either forward recall or backward recall generates a search set (Shiffrin 1970 in Glenberg and Swanson 1986). The greater the number of representation included in a search set, the less likely any one of them is to be recalled (Glenberg and Swanson 1986). 
The concept of primacy-recency is still in dispute. Some researchers prefer the concept of primacy (Murdock 1983; Lewandowsky and Murdock 1989; Johnson 1991; Kardes et al. 1993; McElree and Dosher 1993) whereas others prefer the concept of recency (Bjork and Whitten 1974; Collins and Loftus 1975; Glenberg et al. 1983; 1980; Glenberg and Swanson 1986).

The contradiction leads much research to provide evidence that the process of recall pursues both forward and backward recalls (Rudel and Denckla 1974; Geiselman and Callot 1990; Lewandowsky and Li 1994; Li and Lewandowsky 1995). While Alba and Chattopadhyay (1985; 1986) and Alba and Hutchinson (1987) focused their studies on factors influencing the retention, Nedungadi (1990) investigated factors that ease the recall. Although they begin from a different point of view, to some extent they substantiate the findings of Sujan and Bettman (1989) that a distinctive product gets easier to be recalled. In addition, Nedungadi (1990) clarifies that bearing a particular product in mind will spontaneously remember other products that serve as competitors. The enlightenment is very simple: when an ad gives information, which helps consumers recall a particular brand, other brands that are similar spontaneously arise. If a specific competitor turns out to be more favorable, the initial brand that explicitly informs customers through the ad becomes obsolete.
First-mover products, according to Nedungadi (1990), also enjoy advantages of being brought in mind easily. Based on this idea, Kardes et al. (1993) find that pioneer products have a higher probability in the retrieval set. Kahnemann and Miller (1986) introduce an idea of flexible process that makes use of internally and externally generated retrieval cues to activate information stored in the long-term memory and incorporate it into a particular concept constructed in the working memory. The idea is in accordance with the findings of Collins and Loftus (1975) that the accessibility of brand depends on three factors. The first factor is the strength of activation of the brand node, i.e., the frequency, recency, and salience of brand instantiation and evaluation. The second factor is the strength of association between the brand node and other active nodes. Meanwhile, the last factor is the availability of retrieval cues, i.e., category, brand, and attribute.

\section{Consideration Set}

The consideration set is defined as the set of brands brought to mind in a particular choice occasion (Nedungadi 1990). Sequences of decision making indicate that consumers only consider a few out of available products potential to be a good choice (Campbell 1969 in Nedungadi 1990). This means that under such a judgment, consumers initially observe available products which then result in fewer alternatives. It is possibly in 
Gadjah Mada International Journal of Business, September-December 2009, Vol. 11, No. 3

accordance with the concept of evoked set, i.e., brands that a consumer has in his/her memory, that he/she considers acceptable, and that he/she considers when purchasing the product category (Howard 1989).

While it is a commonly incorrect perception that choice sets are relatively static (Hauser and Wernerfelt 1990), Nedungadi (1990) recommends that choice sets are not fixed, but can change across choice occasions. This idea essentially means that the influence of memory will not be confined to the informational inputs used in brand evaluation, but will extend to the retrieval and consideration of the brands themselves. Consequently, theretrieval and consideration will likely produce different outcomes.

Some other studies follow the stream. Hauser and Wernerfelt (1989 1990), Simonson and Tversky (1992), Assael (1995) scrutinized the consideration set, and confirm that choice sets vary depending on choice occasions. Roberts and Lattin (1991), Brown and Wildt (1992), Kardes et al. (1993), Lehmann and Pan (1994) explored the consideration sets as a construct. The findings show that the product composition has shrunk. There are some products that are supposedly superior because of their specific positions, such as domination, compromise, and assimilation. The subsequent section discusses each of them at a glance.

\section{Attraction Effect}

Huber et al. (1982) and Huber and Puto (1983) are researchers who initially proclaim the attraction effect. Their findings were subsequently investigated by Ratneshwar, Shocker, and Stewart (1987). Respondents were shown two different brands (A and B) that each had two attributes, and they had to choose one of the two. Two weeks later, they had to choose the same two products but with one new brand (C). The new product was dominated by one of the original alternatives (B) but not by the other (A). It is found that the respondents tend to alter their choice. The addition of brand $\mathrm{C}$ increases the attractiveness and choice probability of the now asymmetrically dominating alternative (brand B). Huber and Puto (1983) extended this finding by adding non-dominating alternatives that were relatively inferior to one of the two alternatives in the core set.

The finding alters the regularity that says that a new alternative will not draw more shares from the originals. In other words, one could not increase the choice probability of a product by adding another product in the set (Simonson 1989). This finding also runs counter to the similarity effect, that is, the intuition that a new alternative will draw more from similar alternatives than from dissimilar alternatives (Pan and Lehman 1993). Further- 
more, Huber and Puto (1983) explored more studies on the attraction effect. In their experiment, the new alternative was only relatively inferior to one of the two alternatives in the core set. The finding also depicts the alteration of choice.

The terms asymmetrical dominating product, relatively inferior product, and dominated product are defined as follows. An asymmetrical dominating product is a product that in the perceptual space of two given attributes has superiority, whether in one particular attribute or both, relative to the other products. A relatively inferior product is a product that in the perceptual space of two given attributes has inferiority in only one attribute compared to another product. Meanwhile, a dominated product is a product that in the perceptual space of two given attributes has inferiority in one attribute or both relative to another product.

\section{Compromise Effect}

Simonson (1989) who introduced the compromise effect was inspired by the study of Huber and Puto (1983), in which the attraction effect still works when a relatively inferior alternative comes closer to an existing product. The now-becoming superior product is actually a weak justification since it is not clearly true that one alternative is superior to the other. Interestingly, Huber and Puto (1983) also report that the relatively superior product is labeled as "safe", "compromise" alternative.
When a new alternative $C$ is added to a set containing brands $\mathrm{A}$ and $\mathrm{B}$, where $C$ is relatively inferior to $B$, this will increase the attractiveness of $B$ (attraction effect). The decision making, which is to choose $B$, could be justified in two ways. First, the choice is based on the relative superiority relationship. Second, it is predicated upon the fact that following the addition of the relatively inferior alternative (C), the superior brand (B) can be seen as a compromise choice in terms of its attribute values between brand A and the new inferior alternative, brand C. If the decision maker is uncertain as to which of the two attributes is more important, a selection of a compromise alternative considered to be combining both attributes might be easiest to justify (Stein and Miller in Simonson 1989).

The strength of relative superiority versus compromise as a justification is likely to depend on the particular position of the inferior alternative. The closer and more inferior the added alternative is relative to the superior alternative, the more powerful the relative superiority argument would be relative to the compromise argument, and vice versa (Simonson 1989). Equivalently, when an alternative becomes a compromise or middle option, no matter is there a superiority relationship, the choice probability of the compromise or middle option will increase. 
Gadjah Mada International Journal of Business, September-December 2009, Vol. 11, No. 3

\section{Assimilation Effect}

To make a new inferior alternative in some ways similar to existing brands could be accomplished by assigning the new alternative to be close to the existing brands with which they have similar specifications. Basically, two basic processes that describe how individuals cope with new information are: (1) assimilation and (2) accommodation(Rumelhart and Norman 1972). Assimilation occurs when a new concept is integrated into the present mental scheme whereas accommodation prevails when a new mental scheme is created or the present scheme undergoes substantial modifications to interpret the new concept.

Schemes are cognitive structures representing one's expectation about a domain (Bettman 1979). Over time, an individual is likely to develop a scheme or set of expectations about a product category. These expectations might include hypotheses about the usual values on attributes, the important weights of attributes, and the variability across brands on attributes (Sujan and Bettman 1989). By grouping similar objects, information-processing efficiency as well as cognitive stability is enhanced (Lingle, Altom and Medin 1984; Cohen and Basu 1987). The process of assimilation may occur when new information is slightly-tomoderately discrepant from the category scheme, but is not likely when the new information is strongly discrepant (Sujan and Bettman 1989).
While a sole alternative is less likely to be chosen (Glazer, Kahn and Moore 1991), a brand positioned to be close to another brand is deemed more similar to each other(Pan and Lehmann 1993), and regarded as an assimilated brand (Lehmann and Pan 1994). In addition, being an assimilated alternative will increase the brand's choice probability (Lehmann and Pan 1994).

\section{Choice}

Choice decision is normally based on particular criteria, such as attitudebased and attribute-based criteria (Kardes 2002). While an attitude toward brand is formed by belief and evaluation, the decision then follows the formula of $\mathrm{A}_{0}=\Sigma \mathrm{b}_{\mathrm{i}} \mathrm{e}_{\mathrm{i}}$ (Fazio and Roskos-Ewoldsen 1994). Choice based on attributes distinguishes three types of judgment: (1) compensatory, (2) non-compensatory, and (3) combination process (Peter and Olson 2002). The compensatory process combines all the salient beliefs about the consequences of the choice alternatives to form an overall evaluation or attitude toward each behavioral alternative. On the other hand, the non-compensatory process refers to the imbalance of positive and negative consequences of the choice alternatives. The combination process is a mix of both.

\section{Forming Hypotheses}

When some new products and/or brands are inserted into a particular set which contains several products, the 
existing brands accordingly meet the criteria of primacy. Furthermore, those which are salient may be easily memorable (Collins and Loftus 1975). The term "salient" refers to brand (Nedungadi 1990) and attribute (Alba and Chattopadhyay 1985 1986; Alba and Hutchinson 1987). Therefore, particular products that hold primacy and saliency are inclined to have a greater probability to be retrieved. Accordingly, a hypothesis can be constructed as follows:

H1: The existing brands which are salient have a higher probability to be included in the retrieval set.

On the other hand, new alternatives spontaneously meet the criteria of recency. If the new alternatives are close or similar to the existing brands, the probability of being recalled becomes higher. Therefore, it leads to the following hypothesis:

H2: The new alternatives which are close or seemingly alike to the existing brands have a higher probability to be included in the retrieval set

Huber et al. (1982), and Huber and Puto (1983) show that the choice probability of asymmetrically dominating products increases when a dominated product is added to the set. Likewise, Kardes et al. (1993) proclaim that the most salient product gets easier to be considered. Furthermore, Simonson (1989), Simonson and Tversky (1992), Pan and Lehmann (1993), and Lehmann and Pan (1994) find that the entry of an inferior product strengthens the probability of the dominant product of being considered. The evidence of the research leads to a presumption that not only does the particular existing product get easier to be considered, but a new entrant will also enjoy the consideration if it is superior to the existing product. Consequently, if there are a number of new alternatives entering a set of alternatives, they will have an effect that potentially alters the judgment, particularly because of the new entrants. Whether the new entrants are inferior or superior to existing products, along with the existing products, will produce a new subset in which the most dominant product will be easier to be considered. Therefore, a hypothesis can be formulated as follows:

H3: The entry of a number of new alternatives, whether inferior or superior to an existing product, will make the dominant product easier to be considered.

The studies of Simonson (1989) and Simonson and Tversky (1992) are based on a core set, which consists of two products. Likewise, the new alternative is also one product. While the compromise or middle option has a higher choice probability, if there are then a number of new alternatives coming into a set containing more than two products, the most compromise position will have a greater choice possibility. Therefore, a hypothesis can be established as follows: 
H4: If a number of new alternatives enter into a set, in which both the existing and new alternatives simultaneously create a compromise set, the most compromise option accordingly gets a higher choice possibility.

Referring to the findings of Lingle, Altom and Medin (1984), Cohen and Basu (1987), Sujan and Bettman (1989), Glazer, Kahn and Moore (1991), both Pan and Lehmann (1993) and Lehmann and Pan (1994) imply that a new entrant that is slightly-tomoderately different from a particular existing product, which simultaneously create a subtype group and are regarded as an assimilated brand, enjoys a higher probability of choice.

Likewise, if a number of new alternatives enter into the set, those that are slightly-to-moderately different from particular existing products, which simultaneously create a subtype group, will enjoy an increase in the probability of choice. Therefore:

H5: If a numbers of new alternatives enter into a set, in which some that are similar to particular existing brands create a subtype group with the existing brands, their probability of choice will increase

The last three hypotheses proposed lead to other propositions. While a dominating product gets a higher probability to be considered, the most compromise option also acquires a higher choice possibility, and the as- similated products will be enhanced with respect to their choice probability. Accordingly, which position will have a higher possibility when new entrants simultaneously develop a dominating position in one side, the most compromise in another side, and assimilated position in the other side?

Motivated by the statement of Kardes et al. (1993) that the most salient product is getting easier to be considered, a proposition that the most prominent product has the highest choice possibility can be developed. The dominant position looks more prominent than does the compromise one; therefore, combined with the assimilated position, the most prominent being proposed is simultaneously the dominating position and the assimilated position. If in a particular case, the pose denotes the existing brand, then the assimilated position is automatically overridden. But this is not the case if the most prominent is a new entrant. So, a new hypothesis can be proposed:

H6: When a number of new alternatives' entry into a set simultaneously creates dominating, compromise, and assimilated positions, the products that pose the dominating and assimilated positions have a greater choice probability.

\section{Research Design}

Since this study predominantly investigates the sequence of choice, the multi-stage model of consumer 
choice is harnessed. This study applies a field experiment. Two phases are carried out: (1) preliminary study and (2) experimental study. The first phase consists of three preliminary studies, and each has particular purposes. The objectives of the preliminary study are to: (1) check out the acceptability of two product categories employed, (2) facilitate brands and the types of respondents' knowledge of the two product categories and attributes used in judgment, and (3) find out a set of brands that dominate the market, a set of brands that are supposed to be new brands, and a set of attributes employed in judgment.

The experimental study is run through a within-subject design. It is defined as a study that only employs one group, and the same group is treated differently in different experimental conditions (Singh 1986).

\section{Methods}

Variables affecting the accuracy of data, such as age, sex, location, and life style, should be controlled. While the age variable is controlled by a consistency of mean, the sex variable is controlled by a consistency of sex ratio. In addition, non-bias data of location is facilitated by a consistency of similar colleges, i.e., size and the number of students. Furthermore, the lifestyle variable is controlled by a consistency of mean; this indicator refers to Wells and Tigert's formulation as quoted by Assael (1995), which is based on perceived activities, interests, and opinions.

Data are acquired by delivering questionnaires. An arrangement of product sequence in any question is needed, aiming at describing the most relatively dominating, compromise, assimilated, dominating and assimilated, and compromise and assimilated positions, as well as neutral on the other side. Answers are available on ten scales, from 0 to 10 (Jaccard et al. 1986).

This study carried out two product categories, i.e., freezer and TV. 270 participants were used, including 50 participants of each preliminary study. All of them were college students, including those whose status were employees. Data are analyzed using three approaches. Firstly, probability is analyzed by employing a logit model estimated by the maximum-likelihood method(Greene 2000; Gujarati 1995 1999; Pindyck and Rubinfeld 1998). The dependent variable is the retrieval probability; $p=1$ if retrieved, and 0 otherwise. The independent variables are brand attributes. The model itself is as follows:

$$
\begin{aligned}
& \frac{\operatorname{Ln}\left[\mathrm{P}_{1}\right]}{1-\mathrm{P}_{1}}=\beta_{0}+\beta_{1} \mathrm{X}_{1}+\beta_{2} \mathrm{X}_{1} \ldots \ldots \\
& \ldots \alpha_{n} X_{1}
\end{aligned}
$$

Secondly, the statistical significance of consumer preference score in 
Gadjah Mada International Journal of Business, September-December 2009, Vol. 11, No. 3

the form of respondent's percentage is analyzed to find evidence that supports a particular position as hypothesized in the consideration set. Thirdly, regression analysis with dummy variables is employed to observe statistical significant coefficients on products that pose particular hypothesized positions (Gujarati 1995; 1999). The dependent variable is all products considered by respondents. The independent variables are dummy variables assigned as follows: (1) all brands or types before entry are encoded $0,(2)$ a product, whether the existing product or the new entrant that poses a dominating, compromise, assimilated or dominating, and assimilated position is encoded 1 , and 0 otherwise. The equation is:

$$
Y_{i}=\alpha_{1}+\alpha_{2} D_{i}+\beta_{1} X_{1}+\beta_{2} X_{2}+\ldots . \beta_{n} X_{n}
$$

$\mathrm{Y}_{\mathrm{i}} \quad$ : Products considered by respondents

$\mathrm{X}_{1} \ldots \mathrm{X}_{\mathrm{n}}$ : Existing products and new entrants

$\mathrm{D}=1 \quad$ : If a product has a dominating, compromise, assimi- lated, dominating and assimilated position

$\mathrm{D}=0 \quad$ : Otherwise

\section{Results and Analysis}

\section{a. Preliminary Study}

While the main objective of the first preliminary study is to check out respondents' knowledge of the two categories employed in this study, the second preliminary study investigates further, i.e., to obtain brands that recently exist in the market. It also purports to know brands dominating the market and new entrants according to respondents. In addition, it should produce attributes used in assessing choice.

The number of brands that recently exist in the market is 21 for freezer and 29 for TV. Meanwhile, the brands dominating the market are five for freezer and nine for TV. Brands deemed to be new entrants are three for freezer and eight for TV. Attributes used in assessing choice for any category vary. It is understandable as to some extent respondents refer to their

Table 1. The Dominating Brands Nominated in Experimental Study

\begin{tabular}{|c|c|c|}
\hline No & Category & Brands \\
\hline 1 & Freezer & Panasonic, Sharp, Toshiba, Samsung, Sanyo \\
\hline 2 & TV & Sony, Sharp, Panasonic, Polytron, Toshiba, Akari, Philips \\
\hline
\end{tabular}

Source: Primary data 
Santosa-Factors Affecting Choice in A Multi-Stage Model

Table 2. The New Entrants Nominated on Experimental Study

\begin{tabular}{|c|c|c|}
\hline No & Category & Brands \\
\hline 1 & Freezer & $\begin{array}{l}\text { Sanex, Akari, Sanken Polytron, Denpoo, Electrolux, Hitachi, } \\
\text { LG, Maspion, Panasonic }\end{array}$ \\
\hline 2 & TV & Samsung, Sanken, Digitec, Hitachi, Sanyo, Aiwa \\
\hline
\end{tabular}

Source: Primary data

subjective judgments. However, attributes used are basically not far from four main points, i.e., quality, price, technology, and design.

Since the third preliminary study should be consistent with the previous preliminary studies, the final results obviously appear to be a combination of the three. The objective is then highlighted to generate a set of existing brands, a set of dominating brands (Table 1), a set of new entrants (Table 2 ), and scores of brands based on particular attributes that would be employed in the experimental study. The set of existing brands itself is composed of brands that dominate the market and brands of new entrants.

Parallel with scores as one of the objectives defined in the third preliminary study, the scores are desirably settled in the experimental study's questionnaires. The scores are obtained by dividing total score, which is a sum of numbers between 0-10 favored by the respondents to meet their perceptions about a brand based on particular attributes, by the number of respondents (Appendix 1).

\section{b. Experimental Study}

\section{1) Testing Hypothesis 1}

Two methods are employed: (1) showing the percentage of respondents who successfully recall particular brands and (2) running the logit model. On the freezer category, the dominating brands included in the retrieval set are several. For the sake of efficiency, not all were brought up; rather, only two were tested, i.e., Panasonic $(85,42 \%)$ and Sharp (82\%) (Table 3). Defining $\mathrm{p}=1$ if recalled and $\mathrm{p}=0$ if not recalled, the equation of the logit model for Panasonic is:

$\frac{\operatorname{Ln}\left[\mathrm{P}_{1}\right]}{1-\mathrm{P}_{1}}=-16.22658+2.269191 \mathrm{Pan}$

Based on the respondents' scores, which indicate that more than 81 percent fall on $7,8,9$, and 10 , the calculated probability is found to be 0.955 by averaging.

Likewise, denoting $\mathrm{p}=1$ if recalled and $\mathrm{p}=0$ if not recalled, the equation of the logit model for Sharp is: 
Gadjah Mada International Journal of Business, September-December 2009, Vol. 11, No. 3

Table 3. Freezer Category: Particular Brands Included in the Retrieval Set

\begin{tabular}{|c|c|c|c|}
\hline No & Brand & Number of Respondents & $\%$ \\
\hline 1 & $\overline{\text { Panasonic }}$ & 1025 & $\overline{85.42}$ \\
\hline 2 & Sharp & 984 & 82 \\
\hline 3 & Polytron & 804 & 67 \\
\hline 4 & LG & 790 & 65.83 \\
\hline
\end{tabular}

Source: Data Analysis

Table 4. TV Category: Particular Brands Included in the Retrieval Set

\begin{tabular}{|c|c|c|c|}
\hline No & Brand & Score & $\%$ \\
\hline 1 & Sony & 1097 & 91.42 \\
\hline 2 & Panasonic & 1059 & 88.25 \\
\hline 3 & Samsung & 938 & 78.17 \\
\hline 4 & Digitec & 812 & 67.67 \\
\hline
\end{tabular}

Source: Data Analysis

$$
\frac{\operatorname{Ln}\left[\mathrm{P}_{1}\right]}{1-\mathrm{P}_{1}}=-13.308+1.837 \text { Sharp }
$$

The results show that 82 percent scores fall on 8,9 , and 10 , and the probability of Sharp is equal to 0.962 . This means that both brands (Panasonic and Sharp) are successfully retrieved. While Panasonic gets 96 percent of the probability to be retrieved by most respondents (81\%), Sharp has 96 percent of the probability to be retrieved by 82 percent respondents.

For the TV category, the dominating brands easily recalled are Sony (91.42\%), Panasonic (88.25\%), Sharp (86.17\%), and Polytron (81.92\%) (Table 4). The equation of the logit model for Sony is:

$$
\frac{\operatorname{Ln}\left[\mathrm{P}_{1}\right]}{1-\mathrm{P}_{1}}=-18.775+2.285 \text { Son }
$$

Based on the respondents' scores, which depict that more than 86 percent fall on 8,9 , and 10 , the probability is 0.857 by averaging calculation.

Analogous to the freezer category, brands taken up into the model are just two, i.e., Sony and Panasonic. The equation of Panasonic itself is:

$$
\frac{\operatorname{Ln}\left[\mathrm{P}_{1}\right]}{1-\mathrm{P}_{1}}=-21.562+2.612 \mathrm{Pan}
$$

Subsequently, the score distribution indicates that 82 percent fall on 8 , 9, and 10. Accordingly, by averaging, the probability is found to be 0.875 . 
Both results for the freezer category and for TV category provide evidence that substantiates Hypothesis 1 . In addition, it is in accordance with Kardes et al.'s findings (1993) that the dominant brands would be easily retrieved.

\section{2) Testing Hypothesis 2}

Utilizing criteria such as shape, feature, quality, and color, particular brands are similar to the dominant brands. For the freezer category, the close products are likely to get significant scores, such as Polytron (67\%) and LG (65.83\%) (Table 3). Findings for the TV category are in line with those for the freezer category, i.e., Samsung (78.17\%) and Digitec (67.67\%) (Table 4). By operating the logit model, and in a similar fashion to the testing of Hypothesis 1, this study finds that the probabilities of Polytron, LG, Samsung, and Digitec, are 0.843, $0.804,0.809$, and 0.634 , respec. The results point out evidence supporting Hypothesis 2.

\section{3) Testing Hypotheses 3, 4, and 5}

Method used in these examinations is the percentage analysis through comparison between an assumingly dominating product and dominated products, between compromise products or non-compromise products and base products, and between an assimilating product and assimilated products. In addition, regression analysis with dummy variables is employed to find out statistically significant coefficients on products that pose dominating, compromise, and assimilated prod- ucts. The dependent variable is all products considered by respondents. The independent variables are dummy variables assigned as follows: (1) all brands or types before entry are encoded 0 , (2) a product, whether the existing product or the new entrant that poses a dominating, compromise, and assimilated position is encoded 1 , and 0 otherwise.

The consideration set consists of a set of alternatives where some belong to existing brands and the rest belong to new entrants. For the freezer category, the brands included in the set are Panasonic NRA15KD, Samsung CooltechBio, Toshiba GRC/D169, and Sharp Nice Crystal VR161N, which are utilized as existing alternatives in the set. The new entrants are Polytron PR158, Samsung Bio SR/AGA17, and Denpoo DL198 (see Appendix 2).

For the TV category, the set comprises Sony Trinitron Wega TG 21, Toshiba Bomba 21A3E, LG Turbo Champ 20CA21E, and Sharp Universe 20H200, which are employed as existing alternatives. Meanwhile, Samsung CS 20F2 BB, Polytron Minimax MX5152, Sanken ST2029/39SR, Sony Trinitron Wega HA21P50, Toshiba Bomba 21A3E, Toshiba Bomba 21N3XE, Sharp Wonder 20W25, LG Flatron RT21FA31, and Digitec DN2012 are used as new entrants (see Appendix 3). With reference to particular purposes, the composition and sequence of the set (existing brands and new entrants) are deliberately and diversely determined. The reason for 
Gadjah Mada International Journal of Business, September-December 2009, Vol. 11, No. 3

the variance uniquely serves as a treatment to attain the effects of attraction, compromise, and assimilation.

Evidence seems to support the attraction effect, both for freezer and TV categories. Brands tested are Panasonic NRA15KD, Sharp Nice Crystal VR161N, Sony Trinitron Wega HA21P50, and Toshiba Bomba21A3E (Appendix 4). In comparison with the dominated brands, the results for the dominating brands are statistically significant. Likewise, the four brands have a positive direction, meaning that it has the same direction as the Consideration variable (Table 5). Accordingly, it confirms Hypothesis 3.
The effect of compromise is demonstrated by LG Express Cool and Denpoo DL198 in the freezer category and by Toshiba Bomba 21N3XE in the TV category. In comparison with the bases, the results show significant differences. The three brands also have the same direction as the Consideration variable (Table 5). Actually, the percentage analysis on the TV category yields two brands having significantly differences from the bases, i.e., Toshiba Bomba 21A3E and Toshiba Bomba 21N3XE. Unfortunately, Toshiba Bomba 21A3E is not successful in the regression analysis. Nevertheless, both analyses, i.e., per-

Table 5. Results of Percentage Analysis and Regression Analysis for Hypothesis $3,4,5$

\begin{tabular}{|c|c|c|c|c|c|c|c|}
\hline \multirow[b]{2}{*}{ No } & \multirow[b]{2}{*}{ Effect } & \multirow[t]{2}{*}{ Category } & \multicolumn{2}{|c|}{ Percentage Analysis } & \multicolumn{3}{|c|}{ Regression Analysis } \\
\hline & & & Evidence & $\mathbf{p}$ & Coef. & $\mathbf{t}$ & Sign \\
\hline \multirow[t]{4}{*}{1} & Attraction & Freezer & PanasonicNRA & $0.060 ; 0.001$ & +4.94 & 2.680 & 0.019 \\
\hline & & & Sharp Nice Cryst & $0.024 ; 0.002$ & +5.58 & 3.373 & 0.005 \\
\hline & & TV & Sony Tri Wega & $0.000 ; 0.000$ & +2.81 & 2.15 & 0.053 \\
\hline & & & Toshiba Bomba A & $0.002 ; 0.075$ & +10.3 & 3.45 & 0.005 \\
\hline \multirow[t]{3}{*}{2} & Compromise & Freezer & LG Cool & $0.017 ; 0.005$ & +4.67 & 2.307 & 0.039 \\
\hline & & & Denpoo DL & $0.015 ; 0.003$ & +5.37 & 2.222 & 0.046 \\
\hline & & TV & Toshiba Bomba N & $0.000 ; 0.098$ & +85.1 & 2.680 & 0.0189 \\
\hline \multirow[t]{4}{*}{3} & Assimilated & Freezer & Polytron PR & Not signif & +13.2 & 1.977 & 0.072 \\
\hline & & & LG Express Cool & Not signif & +16.4 & 2.885 & 0.014 \\
\hline & & TV & Sony Tri Wega A & Not signif & +21.80 & 4.29 & 0.001 \\
\hline & & & LG Flatron RT21 & Not signif & +14.25 & 2.49 & 0.030 \\
\hline
\end{tabular}

Source: Data Analysis 
centage analysis and regression analysis, provide evidence that supports Hypothesis 4.

While the attraction and the compromise effects necessitate significant differences, the assimilated effect does not require a significant difference, particularly between assimilated and assimilating brands. The effect is demonstrated by Polytron PR158, LG Express Cool, Sony Trinitron Wega TG 21, and LG Flatron RT21FA31. Moreover, the four brands get the same effect or direction as the Consideration variable, (Table 5). Consequently, there is evidence supporting Hypothesis 5.

\section{4) Testing hypothesis 6}

Employing the same set as that used in examining Hypothesis 5, it is found that Polytron PR158 (freezer category) poses either a dominating or an assimilated position (Table 6). Likewise, Sony Trinitron Wega HA21P50 (TV category) has a similar position. Regression results indicate that both products demonstrate the same direction as the Consideration variable. Furthermore, the probabilities of the two products are the most preferable vis-à-vis the probability of the compromise brands (Table 6). Hence, there is evidence that supports hypothesis 6 .

\section{Implications and Discussion}

The findings demonstrate how a brand should initially undergo reclamation before being considered a nominee for a choice. Decision to purchase obviously begins with the process of sorting to retrieve. Those that succeed in the retrieval process then should undergo a similar process in the consideration stage. While all brands are likely to be chosen, the winner should be specific, which is to possess a dominating assimilated position.

This study apparently supports the findings of Nedungadi (1990), Shocker et al. (1991), and Kardes et al. (1993). However, it develops a more complicated design in at least three aspects.

Table 6. Results of Percentage Analysis, Regression Analysis, and Logit Model for Hypothesis 6

\begin{tabular}{|c|c|c|c|c|c|c|c|c|c|}
\hline & \multirow{3}{*}{$\begin{array}{l}\text { Cate-- } \\
\text { gory }\end{array}$} & \multicolumn{3}{|c|}{ Percentage Analysis } & \multirow{2}{*}{\multicolumn{3}{|c|}{ Regression Analysis }} & \multirow{2}{*}{\multicolumn{2}{|c|}{$\begin{array}{c}\text { Logit Model } \\
\text { Profitability }\end{array}$}} \\
\hline & & \multirow[b]{2}{*}{ Evidence } & \multicolumn{2}{|c|}{$\mathbf{P}$} & & & & & \\
\hline & & & Dom & Ass & Coeff & $t$ & Sig. & DomAs & Compr \\
\hline 1 & Freezer & Polytron PR & $\mathrm{P}=0.029$ & $\mathrm{P}=0.8$ & $+10,68$ & 2,138 & 0.054 & 0.926 & 0.794 \\
\hline 2 & TV & $\begin{array}{l}\text { Sony Trini- } \\
\text { tronWega HA }\end{array}$ & $\mathrm{P}=0.082$ & $\mathrm{P}=0.3$ & $+14,1$ & 2,283 & 0.041 & 0.943 & 0.770 \\
\hline
\end{tabular}

Source: Data Analysis 
Gadjah Mada International Journal of Business, September-December 2009, Vol. 11, No. 3

Firstly, it employs more product categories and brands. Secondly, it involves a complicated selection process in the retrieval phase and the consideration stage. The findings absolutely provoke a relevant marketing strategy. When introducing a new brand into themarket, marketers should consider which brands dominating the market and what characteristics the new brand has. The strategy might be generated as follows. If the new brand is supposedly more superior to the existing brands, it could be posed in two ways. The new brand developed by the same firm as the dominating and existing brand instantly possesses ad- vantages of assimilation and recency whereas the one that comes from a new player should adapt its attributes, which are new modifications to the old brand, to get an assimilation advantage.

This study has a limitation of employing just two attributes in making a choice. Hence, it is suggested that future research involves more than two attributes. While some attributes may be compensated or non-compensated to some extent, this improvement may also facilitate respondents to be more rational and liberated. It is expected that the way a consumer makes a choice of a particular brand after making an evaluation becomes clearer.

\section{Reference}

Alba, J. W. and A. Chattopadhyay 1985. Effects on context and postcategory cues on recall of competing brands. Journal of Marketing Research 22 (August): 340-349.

Alba, J. W. and A. Chattopadhyay. 1986. Salience effect in brand recall. Journal of Marketing Research 23 (November): 363-369.

Alba, J. W. and J. W. Hutchinson. 1987. Dimension of consumer expertise. Journal of Consumer Research 13 (March): 411-454.

Amaldoss, W. J. Bettman, and J. W. Payne. 2005. Biased but efficient: An investigation of coordination facilitated by asymmetric dominance. Mimeo. Duke University

Bettman, J. R. 1979. An Information Processing Theory of Consumer Choice. Massachusetts: Addison-Wesley Publishing Co.

Bjork, R. A. and W. B. Whitten. 1974. Recency sensitive retrieval processes in long term free recall. Cognitive Psychology 6: 173-189.

Brown, J. J. and A. R. Wildt. 1992. Consideration set measurement. Journal of the Academy of Marketing Science 3 (20) (Summer): 235-243.

Cohen, J. B. and K. Basu. 1987. Alternative models of categorization: Toward a contingent processing framework. Journal of Consumer Research 13 (March): 455-473.

Coollins, A. M. and E. F. Loftus. 1975. A spreading-activation theory of semantic processing. Psychological Review 82 (November): 407-428. 
Santosa-Factors Affecting Choice in A Multi-Stage Model

Fazio, R. H., and D. R. Roskos-Ewoldsen. 1994. Acting as we feel, when and how attitudes guide behavior. In Sharon Shavitt and Timothy C. Brook (editor), Persuasion, Psychological Insights and Perspective. Boston: Allyn and Bacon

Geiselman, R. E and R. Callot. 1990. Reverse versus forward recall on script-based texts. Applied Cognitive Psychology 4: 141-144.

Glazer, R., Barbara E. Kahn, and W. L. Moore. 1991. The Influence of external constraints on brand choice: The lone alternative effect. Journal of Consumer Research 18 (June): 119-125.

Glenberg, A. M., M. M. Bradley, T. Kraus, and G. J. Renzaglia. 1983. Study of the longterm recency effect: Support for a contextually guided retrieval hypothesis. Journal of Experimental Psychology: Learning, Memory, and Cognition 10: 16-31.

Glenberg, A. M., M. M. Bradley, J. A. Stevenson, T. A. Kraus, M. J. Tkachuk, A. L. Gretz.

Fish, J. H. and B. M. Turpin. 1980. A two-process account of long-term serial position effects. Journal of Experimental Psychology: Human Learning and Memory 6: 355369.

Glenberg, A. M., and N. G Swanson. 1986. A temporal distinctiveness theory of recency and modality effects. Journal of Experimental Psychology: Learning, Memory, and Cognition 12: 3-15.

Greene, W. H. 2000. Econometric Analysis. New Jersey: Prentice-Hall

Gujarati, D. N. 1995. Basic Econometrics (3 ${ }^{\text {rd }}$ ed.). Singapore: Mc-Graw Hill Book Co.

Gujarati, D. N. 1999. Essentials of Econometrics ( $2^{\text {nd }}$ ed.). Singapore: Mc-Graw Hill Book Co.

Hauser, J. R., and B. Wernerfelt. 1989. The competitive implications of relevant-set/ response analysis. Journal of Marketing Research 26 (November): 391-405.

Hauser, J. R., and B. Wernerfelt. 1990. An evaluation cost model of consideration sets. Journal of Consumer Research 16 (March): 393-408.

Herne, K. 1997. Decoy alternatives in policy choices: Asymmetric domination and compromise effects. European Journal of Political Economy 13: 575-589.

Herne, K. 1999. The effects of decoy gambles on individual choice, experimental. Eco-nomics 2: 31-40.

Highhouse, S. 1996. Context-dependent selection: The effects of decoy and phantom job candidates. Organizational Behavior and Human Decision Processes 65: 68-76.

Howard, J. A. 1989. Consumer in Marketing Strategy. Englewood Cliffs, NJ: PrenticeHall, Inc.

Huber, J., and C. Puto. 1983. Market boundaries and product choice: Illustrating attraction and substitution effects. Journal of Consumer Research 10 (June): 31-44.

Huber, J., J. W. Payne and C. Puto. 1982. Adding asymmetrically dominated alternatives: Violations of regularity and similarity hypothesis. Journal of Consumer Research 9 (June): 90-98.

Jaccard, J. D. Brinberg and L. J. Ackerman. 1986. Assessing attribute importance: A comparison of six methods. Journal of Consumer Research 12 (March): 463-468. 
Gadjah Mada International Journal of Business, September-December 2009, Vol. 11, No. 3

Johnson, G. J. 1991. A distinctive model of serial learning. Psychological Review 98 (2): 204-217

Johnson, E. J. and J. W. Payne. 1985. Effort and accuracy in choice. Management Science 31 (April): 395-414.

Kahneman, D., and D. T. Miller. 1986. Norm theory: Comparing reality to its alternatives. Psychological Review 93 (April): 136-153.

Kardes, F. R. 2002. Consumer Behavior and Managerial Decision Making ( $2^{\text {nd }}$ ed.). New Jersey: Prentice Hall

Kardes, F. R., G. Kalyanaram, M. Chandrashekaran, R. J. Dornoff. 1993. Brand retrieval, consideration set composition, consumer choice, and the pioneering advantage. Journal of Consumer Research 20 (June): 62-74.

Kim, S., and L. Hasher. 2005. The attraction effect in decision making: Superior performance by older adults. Q J Exp Psychol A 58 (1) (January): 120-133.

Kohler, W. R. 2007. Why does context matter? Attraction effects and binary comparisons. Working Paper Series. Institute for Empirical Research in Economics, University of Zurich. July

Lehmann, D. R., and Y. Pan. 1994. Context effects, new brand entry, and consideration sets. Journal of Marketing Research XXXI (August): 364-374.

Lewandowsky, S., and B. B. Murdock Jr. 1989. Memory for serial order. Psychological Review 96 (1): 25-57.

Lewandowsky, S., and L. Shu-Chen. 1994. Memory for serial order revisited. Psychological Review 96: 25-57.

Lingle, J. M., M. W. Altom, and D. L Medin. 1984. Of cabbages and kings: Assessing the extendibility of natural object concept models to social things. In Robert S Wyer and Thoms K. Scull Hillsdale (Ed.), Handbook of Social Cognition 1. NJ: Erlbaum: 71118.

Li, S-C., and S. Lewandowsky. 1995. Forward and backward recall: Different retrieval processes. Journal of Experimental Psychology: Learning, Memory, and Cognition 21. (4): 837-847.

Lunn, J. A. 1974. Consumer decision-process models. In Jagdish N. Sheth (Ed.), Models of Buyer Behavior, Conceptual, Quantitative, and Empirical. New York: Harper and Row Publishers: 34-69.

March, J. G. 1978. Bounded rationality, ambiguity, and the engineering of Choice. Bell Journal of Economics 9 (2): 587-608.

McElree, B., and B. A. Dosher. 1993. Serial retrieval process in the recovery of order information. Journal of Experimental Psychology: General 122 (3): 291-315.

Montgomery, H. 1983. Decision rules and the search for a dominance structure: Towards a process model of decision making. In P. C. Humphreys et al. (Ed.), Analyzing and Aiding Decision Processes. Amsterdam, the Netherlands: North-Holland: 343-369.

Murdock. Jr, B. B. 1983. A distributed memory model for serial-order information. Psychological Review 90 (4): 316-338. 
Santosa-Factors Affecting Choice in A Multi-Stage Model

Nedungadi, P. 1990. Recall and consumer consideration sets: Influencing choice without altering brand evaluations. Journal of Consumer Research 17 (December): 263-276.

Pan, Y., and D. R. Lehmann. 1993. The influence of new brand entry on subjective brand judgments. Journal of Consumer Research 20 (June): 76-86

Pan, Y., S. O’Curry, and R. Pitts. 1995. The attraction effect and political choice in two elections. Journal of Consumer Psychology: 85-101.

Peter, J. P., and J. C. Olson. 2002. Consumer Behavior and Marketing Strategy (6 $6^{\text {th }}$ ed.). New York: McGraw-Hill Book Company.

Pindyck, R. S., and D. L. Rubinfeld. 1998. Econometric Models and Economic Forecasts. Boston: Irwin McGraw-Hill

Ratneshwar, S., A. D. Shocker, and D. W. Stewart. 1987. Toward understanding the attraction effect: The implication of product stimulus meaningfulness and familiarity. Journal of Consumer Research 13 (March): 520-533.

Restle, F. 1975. Learning: Animal Behavior and Human Cognition. New York: Mc GrawHill

Roberts, J. H., and J. M. Lattin. 1991. Development and testing of a model of consideration set composition. Journal of Marketing Research 28 (November): 429-440.

Rudel, R. G., and M. B. Denckla. 1974. Relation on forward and backward digit repetition to neurological impairment in children with learning disability. Neuropsychologia 12: 109-118.

Rumelhart, D. E., and D. A Norman. 1972. Accretion, tuning and restructuring: Three models of learning. In E Tulving and W. Donaldson (Ed.), Organization of Memory. New York: Academic Press: 197-246

Savage, L. J. 1954. Foundations of Statistics. New York: John Wiley

Shocker, A., M. Ben-Akiva, B. Buccaro, and P. Nedungadi. 1991. Consideration sets influences on consumer decision-making and choice: Issues, models, and suggestions. Marketing Letters 2 (3): 181-197.

Simonson, I. 1989. Choice based on reasons: The case of attraction and compromise effects. Journal of Consumer Research 7 (September): 158-174.

Simonson, I., and A. Tversky. 1992. Choice in context: Tradeoff contrast and extremeness aversion. Journal of Marketing Research 29 (August): 281-295.

Singh, A. K. 1986. Test Measurements and Research Methods in Behavioral Sciences. New Delhi: Tata McGraw-Hill Publishing Company Limited

Slovic, P. 1975. Choice between equally-Valued alternatives. Journal of Experimental Psychology: Human Perception and Performance 1 (3): 280-287.

Slovic, P., B. Fischhoff, and S. Lichtenstein. 1982. Response mode, framing, and information processing effects in risk assessment. In Robin M. Hogarth New Directions in Methodology of social and Behavioral Science: The Framing of Questions and the Consistency of Response. San Francisco: Jossey-Bass

Sujan, M., and J. R. Bettman. 1989. The effects of brand positioning strategies on consumer's brand and category perceptions: Some insights from schema Research. Journal of Marketing Research XXVI (November): 454-467. 
Gadjah Mada International Journal of Business, September-December 2009, Vol. 11, No. 3

\section{APPENDIX 1. Brands Scores of TV Category Based on Quality}

\begin{tabular}{|c|c|c|c|}
\hline No & Brands & Score & Aver \\
\hline 1 & Akari & 256 & 7.11 \\
\hline 2 & Aiwa & 350 & 8.33 \\
\hline 3 & Digitec & 271 & 7.74 \\
\hline 4 & Fujitec & 201 & 6.09 \\
\hline 5 & Hitachi & 262 & 6.89 \\
\hline 6 & Intel & 186 & 5.64 \\
\hline 7 & JVC & 305 & 8.24 \\
\hline 8 & LG & 299 & 7.29 \\
\hline 9 & Mitsubishi & 186 & 6.89 \\
\hline 10 & Panasonic & 378 & 8.79 \\
\hline 11 & Philips & 326 & 8.81 \\
\hline 12 & Polytron & 343 & 7.79 \\
\hline 13 & Panda & 94 & 4.7 \\
\hline 14 & Sony & 482 & 9.84 \\
\hline 15 & Sharp & 343 & 7.79 \\
\hline 16 & Samsung & 322 & 7.85 \\
\hline 17 & Sanyo & 224 & 7.0 \\
\hline 18 & Sanken & 184 & 6.81 \\
\hline 19 & Sanex & 106 & 5.05 \\
\hline 20 & Sunkyu & 79 & 4.16 \\
\hline 21 & Toshiba & 376 & 9.16 \\
\hline
\end{tabular}

Source: Primary Data 
Santosa-Factors Affecting Choice in A Multi-Stage Model

APPENDIX 2. The Profile of Freezers Based on Price and Quality for H3

\begin{tabular}{|c|c|c|c|}
\hline Brand/Type & Description & $\begin{array}{c}\text { Price } \\
\text { (Rp) }\end{array}$ & $\begin{array}{c}\text { Quality } \\
\text { Scaled from } 0 \\
\text { (the lowest) to } 10 \\
\text { (the highest) }\end{array}$ \\
\hline Panasonic NRA15KD & 1 door & 1.600 .000 & 9 \\
\hline Sharp Nice Crystal VR161N & 1 door & 1.728 .000 & 9 \\
\hline Samsung Bio SR/AGA17 & 1 door & 1.481 .000 & 8 \\
\hline Denpoo DL 198 & 1 door & 1.644 .000 & 8 \\
\hline Polytron PR 158 & 1 door & 1.456 .000 & 8 \\
\hline Toshiba GRC/D169 & 1 door & 1.612 .000 & 9 \\
\hline
\end{tabular}

Source: Preliminary Study processed

APPENDIX 3. The Profile of TV Based on Price and Quality for H3

\begin{tabular}{|c|c|c|c|}
\hline Brand/Type & Description & $\begin{array}{l}\text { Price } \\
\text { (Rp) }\end{array}$ & $\begin{array}{c}\text { Quality } \\
\text { Scaled from } 0 \\
\text { (the lowest) to } 10 \\
\text { (the highest) }\end{array}$ \\
\hline Sony Trinitron Wega TG 21 & $\begin{array}{l}\text { 21"/Stereo/ } \\
\text { Flat }\end{array}$ & 3.800 .000 & 10 \\
\hline Toshiba Bomba 21A3E & $\begin{array}{l}\text { 21"/Stereo/ } \\
\text { Concave }\end{array}$ & 2.274 .000 & 9 \\
\hline Sharp Universe $20 \mathrm{H} 200$ & $\begin{array}{l}\text { 20"/Mono/ } \\
\text { Concave }\end{array}$ & 1.883 .000 & 8 \\
\hline Samsung CS 20F2 BB & $\begin{array}{l}\text { 20"/mono/ } \\
\text { Concave }\end{array}$ & 1.756 .000 & 8 \\
\hline Polytron Minimax MX 5152 & $\begin{array}{l}21 " / \text { mono/ } \\
\text { Semiconcave }\end{array}$ & 2.097 .000 & 8 \\
\hline Sanken ST 2029/39SR & $\begin{array}{l}\text { 20"/Stereo/ } \\
\text { Concave }\end{array}$ & 1.900 .000 & 7 \\
\hline Digitex DN 2012 & $\begin{array}{l}\text { 20"/mono/ } \\
\text { Concave }\end{array}$ & 1.650 .000 & 8 \\
\hline
\end{tabular}

Source: Preliminary Study processed 
Gadjah Mada International Journal of Business, September-December 2009, Vol. 11, No. 3

\section{APPENDIX 4. Dominating vs Dominated}

\section{TV Category}

(a) Sony vs Samsung (SONSAM)

$\begin{array}{lcccc}\text { Variable } & \begin{array}{c}\text { Number } \\ \text { of Cases }\end{array} & \text { Mean } & \text { SD } & \text { SE of Mean } \\ \text { Group 1 } & 20 & 9.325 & 0.922 & 0.206 \\ \text { Group 2 } & 20 & 7.000 & 1.170 & 0.262\end{array}$

Mean Difference $=2.3250$

Levene's Test for Equality of Variances: $F=0.333 \quad \mathrm{P}=0.567$

t-test for Equality of Means $\quad 95 \%$

$\begin{array}{cccccc}\text { Variances } & \text { t-value } & \text { df } & \text { 2-Tail Sig } & \text { SE of Diff } & \text { CI for Diff } \\ \text { Equal } & 6.98 & 38.00 & 0.000 & 0.333 & (1.651,2.999) \\ \text { Unequal } & 6.98 & 36.03 & 0.000 & 0.333 & (1.649,3.001)\end{array}$

Indication: the difference of two means is very significant a Ho rejected

(b) Sony vs Polytron (SONPOLY)

\begin{tabular}{|c|c|c|c|c|c|c|}
\hline \multicolumn{2}{|c|}{ Variable } & $\begin{array}{l}\text { Imber } \\
\text { Cases }\end{array}$ & Mean & SD & \multicolumn{2}{|c|}{ SE of Mean } \\
\hline \multicolumn{2}{|c|}{ Group 1} & 20 & 9.325 & 0.922 & \multicolumn{2}{|c|}{0.206} \\
\hline \multicolumn{2}{|c|}{ Group 2} & 20 & 7.300 & 1.838 & \multicolumn{2}{|c|}{0.411} \\
\hline \multicolumn{7}{|c|}{ Mean Difference $=2.0250$} \\
\hline \multicolumn{4}{|c|}{ t-test for Equality of Means } & \multicolumn{3}{|c|}{$95 \%$} \\
\hline Variances & t-value & df & 2-Tail Sig & SE of & Diff & CI for Diff \\
\hline Equal & 4.40 & 38.00 & 0.000 & 0.4 & & $(1.094,2.956)$ \\
\hline Unequal & 4.40 & 27.98 & 0.000 & 0.4 & & $(1.083,2.967)$ \\
\hline
\end{tabular}

Indication: the difference of two means is very significant a Ho rejected 
Santosa-Factors Affecting Choice in A Multi-Stage Model

Continued from APPENDIX 4

(c) Sony vs Polytron (SONSANK)

\begin{tabular}{|c|c|c|c|c|c|}
\hline \multicolumn{2}{|l|}{ Variable } & $\begin{array}{l}\text { Imber } \\
\text { Cases }\end{array}$ & Mean & SD & SE of Mean \\
\hline \multicolumn{2}{|l|}{ Group 1} & 20 & 9.325 & 0.922 & 0.206 \\
\hline \multicolumn{2}{|l|}{ Group 2} & 20 & 5.700 & 2.185 & 0.489 \\
\hline \multicolumn{6}{|c|}{ Mean Difference $=3.6250$} \\
\hline \multicolumn{4}{|c|}{ t-test for Equality of Means } & \multicolumn{2}{|l|}{$95 \%$} \\
\hline Variances & t-value & df & 2-Tail Sig & SE of Diff & CI for Diff \\
\hline Equal & 6.84 & 38.00 & 0.000 & 0.530 & $(2.551,4.699)$ \\
\hline Unequal & 6.84 & 25.55 & 0.000 & 0.530 & $(2.535,4.715)$ \\
\hline
\end{tabular}

Indication: the difference of two means is very significant a Ho rejected

(d) Sony vs Digitec (SONDIGIT)

$\begin{array}{lcccc}\text { Variable } & \begin{array}{c}\text { Number } \\ \text { of Cases }\end{array} & \text { Mean } & \text { SD } & \text { SE of Mean } \\ \text { Group 1 } & 20 & 9.325 & 0.922 & 0.206 \\ \text { Group 2 } & 20 & 6.375 & 1.806 & 0.404\end{array}$

Mean Difference $=2.9500$

Levene's Test for Equality of Variances: $F=4.459 \mathrm{P}=.041$

t-test for Equality of Means $\quad 95 \%$

\begin{tabular}{ccccrc} 
Variances & t-value df & \multicolumn{2}{c}{ 2-Tail Sig } & SE of Diff & CI for Diff \\
Equal & 6.51 & 38 & 0.000 & 0.453 & $(2.032,3.868)$ \\
Unequal & 6.51 & 28.27 & 0.000 & 0.453 & $(2.021,3.879)$
\end{tabular}

Indication: the difference of two means is very significant a Ho rejected 
Gadjah Mada International Journal of Business, September-December 2009, Vol. 11, No. 3

\section{Continued from APPENDIX 4}

(2) t-test Toshiba with Samsung, Polytron, Sanken, Digitec

Group A: Dom

(a) Toshiba vs Samsung (TOSISAM)

\begin{tabular}{|c|c|c|c|c|}
\hline Variable & $\begin{array}{l}\text { Number } \\
\text { of Cases }\end{array}$ & Mean & SD & SE of Mean \\
\hline Group 1 & 20 & 8.175 & 1.067 & 0.239 \\
\hline Group 2 & 20 & 7.000 & 1.170 & 0.262 \\
\hline \multicolumn{5}{|c|}{ Mean Difference $=1.1750$} \\
\hline
\end{tabular}

$\begin{array}{cccccc}\text { Variances } & \text { t-value } & \text { df } & \text { 2-Tail Sig } & \text { SE of Diff } & \text { CI for Diff } \\ \text { Equal } & 3.32 & 38 & 0.002 & 0.354 & (0.458,1.892) \\ \text { Unequal } & 3.32 & 37.68 & 0.002 & 0.354 & (0.458,1.892)\end{array}$

Indication: the difference of two means is very significant a Ho rejected

(b) Toshiba vs Polytron (TOSPOLY)

\begin{tabular}{lcccc} 
Variable & of Cases & Mean & SD & SE of Mean \\
Group 1 & 20 & 8.175 & 1.067 & 0.239 \\
Group 2 & 20 & 7.300 & 1.838 & 0.411 \\
Mean Difference $=.8750$ & & & \\
Levene's Test for Equality of Variances: $\mathrm{F}=8.644$ & $\mathrm{P}=.006$ \\
t-test for Equality of Means & \multicolumn{4}{c}{$95 \%$}
\end{tabular}

$\begin{array}{cccccc}\text { Variances } & \text { t-value } & \text { df } & \text { 2-Tail Sig } & \text { SE of Diff } & \text { CI for Diff } \\ \text { Equal } & 1.84 & 38 & 0.073 & 0.475 & (-0.087,1.837) \\ \text { Unequal } & 1.84 & 30.50 & 0.075 & 0.475 & (-0.095,1.845)\end{array}$

Indication: the difference of two means is very significant a Ho rejected 
Santosa-Factors Affecting Choice in A Multi-Stage Model

Continued from APPENDIX 4

(c) Toshiba vs Sanken (TOSSANKE)

Number

$\begin{array}{lcccc}\text { Variable } & \text { of Cases } & \text { Mean } & \text { SD } & \text { SE of Mean } \\ \text { Group } 1 & 20 & 8.175 & 1.067 & 0.239 \\ \text { Group } 2 & 20 & 5.700 & 2.185 & 0.489\end{array}$

Mean Difference $=2.4750$

Levene's Test for Equality of Variances: $F=4.056 \mathrm{P}=.051$

t-test for Equality of Means $\quad 95 \%$

$\begin{array}{cccccc}\text { Variances } & \text { t-value } & \text { df } & \text { 2-Tail Sig } & \text { SE of Diff } & \text { CI for Diff } \\ \text { Equal } & 4.55 & 38 & 0.000 & 0.544 & (1.374,3.576) \\ \text { Unequal } & 4.55 & 27.58 & 0.000 & 0.544 & (1.361,3.589)\end{array}$

Indication: the difference of two means is very significant a Ho rejected

(d) Toshiba vs Digitec (TOSDIGIT)

\begin{tabular}{|c|c|c|c|c|}
\hline \multicolumn{2}{|c|}{ Number } & \multirow[b]{2}{*}{ Mean } & \multirow[b]{2}{*}{ SD } & \multirow[b]{2}{*}{ SE of Mean } \\
\hline Variable & of Cases & & & \\
\hline Group 1 & 20 & 8.175 & 1.067 & 0.239 \\
\hline Group 2 & 20 & 6.375 & 1.806 & 0.404 \\
\hline \multicolumn{5}{|c|}{ Mean Difference $=1.8000$} \\
\hline -test for $\mathrm{E}$ & ity of $\mathrm{M}$ & & & \\
\hline
\end{tabular}

$\begin{array}{cccccc}\text { Variances } & \text { t-value } & \text { df } & \text { 2-Tail Sig } & \text { SE of Diff } & \text { CI for Diff } \\ \text { Equal } & 3.84 & 38 & 0.000 & 0.469 & (.850,2.750) \\ \text { Unequal } & 3.84 & 30.83 & 0.001 & 0.469 & (.843,2.757)\end{array}$

Indication: the difference of two means is very significant a Ho rejected 
Gadjah Mada International Journal of Business, September-December 2009, Vol. 11, No. 3

\section{Continued from APPENDIX 4}

Freezer Category

PANSAMSUNGBIODOM

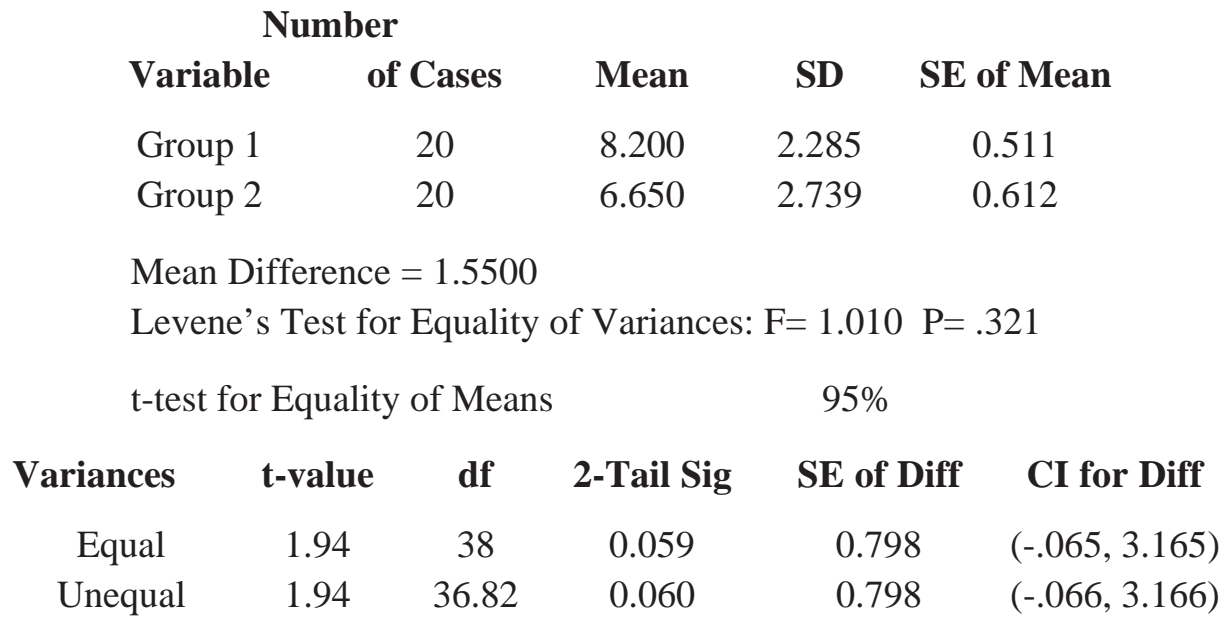

\section{PANDEMPODOM}

\begin{tabular}{lcccc}
\multicolumn{2}{c}{ Number } & & & \\
Variable & of Cases & Mean & SD & SE of Mean \\
Group 1 & 20 & 8.200 & 2.285 & 0.511 \\
Group 2 & 20 & 5.200 & 2.764 & 0.618
\end{tabular}

Mean Difference $=3.0000$

Levene's Test for Equality of Variances: $F=1.408 \mathrm{P}=.243$

t-test for Equality of Means $\quad 95 \%$

$\begin{array}{cccccc}\text { Variances } & \text { t-value } & \text { df } & \text { 2-Tail Sig } & \text { SE of Diff } & \text { CI for Diff } \\ \text { Equal } & 3.74 & 38 & 0.001 & 0.802 & (1.376,4.624) \\ \text { Unequal } & 3.74 & 36.70 & 0.001 & 0.802 & (1.375,4.625)\end{array}$


Santosa-Factors Affecting Choice in A Multi-Stage Model

Continued from APPENDIX 4

SHARPCRYSTAL SAMSUNG BIODOM

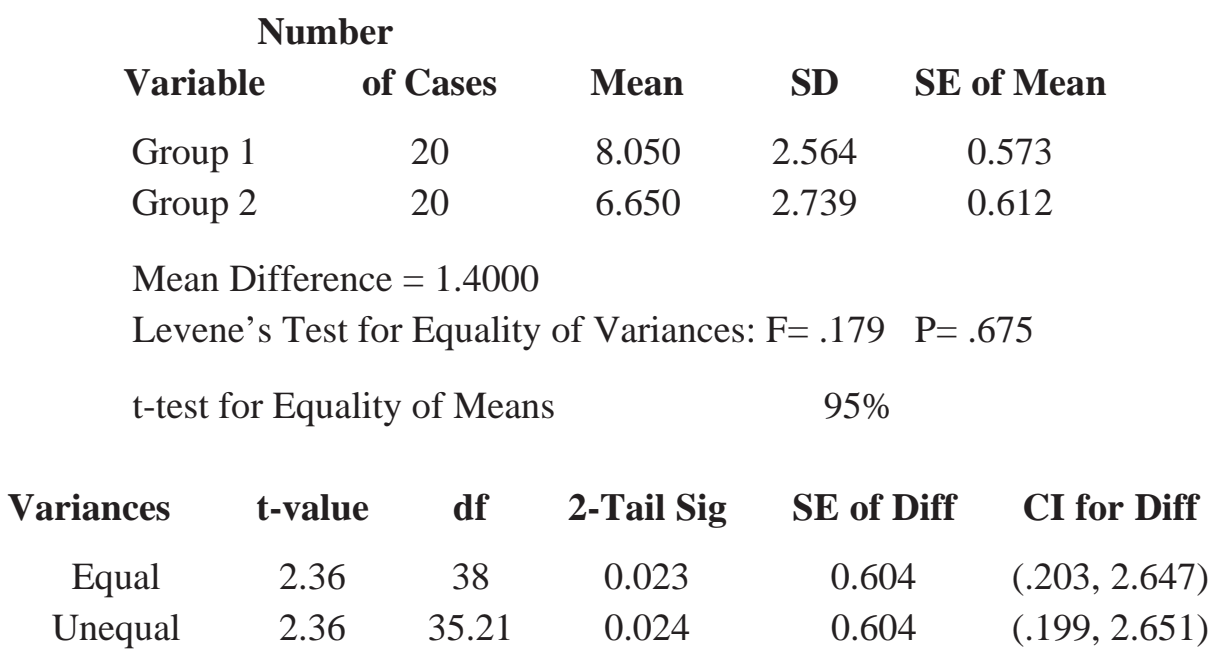

